\title{
VIDEO EDUKASI ATRAKTIF DALAM MENINGKATKAN KETERAMPILAN CUCI TANGAN
}

\author{
Fika Aulia, Mirawati, Bening Prawita Sari \\ Univesitas Muhammadiyah Bajarmasin, \\ Jl. S.Parman Komplek Rs.Islam Banjarmasin Kalimantan Selatan, 0511-3363002 \\ fika_aulia@umbjm.ac.id
}

\begin{abstract}
ABSTRAK
Perilaku Hidup Bersih Sehat (PHBS) merupakan upaya untuk membentuk perilaku masyarakat yang peduli dengan kesehatan. Salah satu upaya PHBS adalah Cuci Tangan Pakai Sabun (CTPS). Praktik mencuci tangan dengan sabun perlu diterapkan sejak usia dini sebagai upaya mencegah penularan penyakit berbasis lingkungan. Salah satu kelompok yang cocok keberhasilan penyampaian pesan CTPS adalah anak sekolah misalnya dengan memberikan edukasi melalui video edukasi atraktif. Penelitian ini menggunakan desain Quasy Experiment dengan menggunakan model rancangan one group pretest-posttest. Alat pengumpulan data menggunakan Checklist Keterampilan Cuci Tangan. Diperoleh hasil sebagian besar responden berketerampilan kurang dalam mencuci tangan sebanyak 26 anak (74,3\%) sedangkan sesudah diberi perlakuan sebagian besar dari responden yaitu 29 anak (82,9\%) berketerampilan baik dalam mencuci tangan. Nilai uji beda Wilcoxon Signed Rank Test didapatkan $p$ value $(0,000)$ dimana nilai $p$ value $<0,05$ sehingga dapat disimpulkan bahwa ada pengaruh penyuluhan cuci tangan menggunakan media video atraktif terhadap keterampilan cuci tangan pada siswa Madrasah Diniyah Awaliyah Belawang.
\end{abstract}

Kata kunci: video atraktif; cuci tangan; keterampilan

\section{ATTRACTIVE EDUCATIONAL VIDEOS IN IMPROVING HANDWASHING SKILLS}

\begin{abstract}
Clean and Healthy Behaviour is an effort to shape the behaviour of people who care about health. One of its efforts is Hand Washing with Soap. The practice of washing hands with soap needs to be applied from an early age as an effort to prevent the transmission of environmental-based diseases. One group that fits the success of delivering Hand Washing with Soap messages is school children, for example by providing education through attractive educational videos. This study used a Quasy Experiment design using a one group pretest-posttest design model. The data collection tool used the Hand Washing Skills Checklist. The results showed that most of the respondents had poor skills in washing their hands as many as 26 children (74.3\%) while after being treated, most of the respondents, namely 29 children (82.9\%) had good hand washing skills. The value of the different Wilcoxon Signed Rank Test obtained $p$ value (0.000) where the $p$ value $<0.05$ so it can be concluded that there is an effect of hand washing counselling using attractive video media on hand washing skills in Madrasah Diniyah Awaliyah Belawang students.
\end{abstract}

Keywords: attractive video; washing hands; Skills

Jurnal SMART Kebidanan is licensed under a Creative Commons Attribution-ShareAlike 4.0 International License. 


\section{LATAR BELAKANG}

Perilaku Hidup Bersih dan Sehat (PHBS) merupakan kebiasaan hidup perorangan, keluarga dan masyarakat yang berorientasi sehat, bertujuan untuk meningkatkan, memelihara dan melindungi kesehatan. Permasalahan perilaku kesehatan pada anak usia Sekolah Dasar biasanya berkaitan dengan kebersihan perorangan, lingkungan dan munculnya berbagai penyakit yang sering menyerang anak usia sekolah, ternyata umumnya berkaitan dengan PHBS (Kemenkes, 2016).

Menurut (Permenkes RI No. 3 Tahun 2014) Sanitasi Total Berbasis Masyarakat (STBM) adalah pendekatan untuk mengubah perilaku hygiene dan sanitasi melalui pemberdayaan masyarakat dengan cara pemicuan. STBM mempunyai lima pilar yaitu Stop Buang Air Besar Sembarangan, Cuci Tangan Pakai Sabun (CTPS), Pengelolaan Air Minum dan Makanan Rumah Tangga, Pengamanan Sampah Rumah Tangga dan Pengamanan Limbah Cair Rumah Tangga (Kemenkes RI, 2016).

Mencuci tangan pakai air saja (tanpa sabun) dinilai tidak efektif, penggunaan sabun selain membantu singkatnya waktu cuci tangan, dengan menggosok jemari menggunakan sabun menghilangkan kuman yang tidak tampak, minyak, lemak maupun kotoran di permukaan kulit, serta meninggalkan bau wangi. Perpaduan antara kebersihan bau wangi dan perasaan segar merupakan hal positif yang diperoleh setelah menggunakan sabun (Kemenkes RI, 2016)

Mencuci tangan dengan sabun berfungsi untuk menghilangkan kuman penyakit yang ada di tangan (Karala, 2015). Praktik mencuci tangan dengan sabun perlu diterapkan sejak usia dini sebagai upaya mencegah penularan penyakit berbasis lingkungan. WHO (World Health Organization) menyatakan perilaku cuci tangan pakai sabun dapat menurunkan angka kejadian penyakit diare sebanyak $45 \%$. Salah satu kelompok termasuk kelompok sekunder yang tidak kalah pentingnya dalam keberhasilan penyampaian pesan CTPS adalah anak sekolah.
Penyuluhan kesehatan melalui komunitas sekolah merupakan cara efektif sebagai upaya pengembangan perilaku hidup sehat. Sekolah merupakan lembaga pendidikan formal yang merupakan tempat untuk menanamkan pengetahuan untuk membentuk perilaku melalui peraturan-peraturan. Anak sekolah merupakan kelompok yang paling peka menerima perubahan (mudah dibimbing, diarahkan, dan ditanamkan) kebiasaan hidup sehat (Notoatmodjo, 2010)

Upaya yang dilakukan untuk meningkatkan pengetahuan siswa tentang cuci tangan pakai sabun adalah dengan melakukan penyuluhan. Agar penyuluhan dapat mencapai hasil yang maksimal diperlukan metode dan media pembelajaran yang tepat.

Video merupakan media kreatif yang dapat digunakan untuk meningkatkan motivasi belajar, sehingga penyuluhan dengan menggunakan media video dinilai lebih menarik sehingga dapat menumbuhkan pemahaman kepada audience. Irfan, Mashudi, Murtiningsih (2016) mengemukakan bahwa video merupakan media yang menyenangkan bagi siswa sehingga dapat membangkitkan rasa ingin tahu dan antusias terhadap pembelajaran dan terjadi peningkatan hasil belajar.

Video dapat menjelaskan sesuatu yang bersifat abstrak menjadi terkesan nyata (Febriani, 2017), oleh karena itu video sangat efektif digunakan untuk siswa Sekolah Dasar yang masih berada pada tahap operasional konkret. Hasil penelitian Pratiwi (2015) menunjukkan bahwa media video pembelajaran merupakan salah satu pengembangan dari media audiovisual yang dapat mewakili apa saja yang kurang mampu guru sampaikan mengenai contoh-contoh secara lebih konkret. Siswa lebih senang dengan hal yang lebih konkret dibandingkan dengan mendengarkan dan mencatat. Rasa ingin tahu siswa saat media video pembelajaran ditayangkan dijadikan untuk menggali pengetahuan dan pengalaman siswa dalam kehidupan sehari-hari sehingga dapat meningkatkan keterampilan.

Tuntutan zaman di era milenial saat ini adalah tenaga kesehatan harus mampu 
menyesuaikan dengan perkembangan teknologi yang ada. Dalam penelitian ini pendidikan kesehatan dilakukan dengan menggunakan media video atraktif sehingga lebih menarik untuk anak-anak. Lagu yang ada dalam video penelitian ini mampu membuat anak lebih mudah mengingat mengenai langkah keterampilan cuci tangan yang diajarkan. Berdasarkan latar belakang di atas peneliti tertarik untuk melakukan penelitian tentang "Video Edukasi Atraktif Dalam Meningkatkan Keterampilan Siswa Madrasah Diniyah Awaliyah Belawang".

\section{METODE}

Penelitian ini dilakukan pada bulan Desember 2019 sampai dengan Maret 2020 di Madrasah Diniyah Awaliyah Desa Belawang Kabupaten Barito Kuala Kalimantan Selatan. Desain penelitian menggunakan Quasy Experiment dengan menggunakan model rancangan one group pretest-posttest design. Dalam rancangan ini tidak ada kelompok pembanding, tetapi dilakukan observasi pertama (pretest) yang memungkinkan peneliti dapat menguji perubahan-perubahan yang terjadi setelah adanya perlakuan. Teknik sampling yang digunakan dalam penelitian ini menggunakan Non Probability Sampling dengan teknik purposive sampling yaitu dengan menentukan target elemen populasi yaitu siswa kelas 1 dengan jumlah sampel sebanyak 35 siswa.

Variabel bebas pada penelitian ini adalah penyuluhan menggunakan media video atraktif, sedangkan variabel terikatnya adalah keterampilan mencuci tangan yang benar. Video atraktif tentang langkah mencuci tangan yang digunakan dalam penelitian ini berpedoman pada panduan WHO guidelines on Cuci Tangan in Health Care tahun 2009. Alat ukur yang digunakan untuk menilai keterampilan cuci tangan berupa lembar checklist yang dibuat berdasarkan langkah mencuci tangan panduan WHO guidelines on Cuci Tangan in Health Care tahun 2009 sehingga sudah relevan.

Observasi menggunakan lembar checklist dilakukan dengan cara menilai secara langsung subjek penelitian sebelum dan setelah diberikan intervensi. Pretest dilakukan sebelum subjek mendapatkan penyuluhan cuci tangan menggunakan media video atraktif, sedangkan post test dilakukan setelah diberikannya intervensi penyuluhan cuci tangan menggunakan media video atraktif.

\section{HASIL}

\section{Karakteristik Responden}

Karakteristik responden berdasarkan jenis kelamin dan Umur dalam penelitian ini dapat dilihat pada tabel berikut:

Tabel 1. Distribusi Frekuensi Karakteristik Responden $(n=35)$

\begin{tabular}{ccc}
\hline $\begin{array}{c}\text { Karakteristik } \\
\text { Responden }\end{array}$ & Jumlah & $\begin{array}{c}\text { Presentase } \\
(\%)\end{array}$ \\
\hline $\begin{array}{c}\text { Jenis Kelamin } \\
\text { Laki-laki }\end{array}$ & 18 & $51,4 \%$ \\
Perempuan & 17 & $48,6 \%$ \\
\hline Umur & & \\
6 Tahun & 3 & $8,6 \%$ \\
6,5 Tahun & 1 & $2,9 \%$ \\
7 Tahun & 31 & $88,6 \%$ \\
\hline
\end{tabular}

Tabel 1 menunjukkan bahwa jenis kelamin responden pada penelitian ini berjumlah seimbang antara laki-laki dan perempuan. Jumlah responden meliputi 18 laki-laki $(51,4 \%)$ dan 17 (48,6\%) perempuan.

\section{Keterampilan Siswa Mencuci Tangan Sebelum dan Sesudah Penyuluhan}

Pengukuran tingkat keterampilan mencuci tangan sebelum dan sesudah penyuluhan dengan menggunakan video atraktif dilakukan dengan menggunakan checklist yang sesuai dengan keterampilan langkah cuci tangan panduan WHO tahun 2009. Hasil keterampilan dapat dilihat pada tabel berikut:

Tabel 2. Gambaran Tingkat Keterampilan Mencuci Tangan responden $(n=35)$

\begin{tabular}{cccccccccc}
\hline Kategori & \multicolumn{4}{c}{ Tingkat keterampilan } & \multicolumn{2}{c}{ Total } \\
\cline { 2 - 9 } & \multicolumn{3}{c}{ Baik } & \multicolumn{3}{c}{ Cukup } & \multicolumn{2}{c}{ Kurang } \\
& $\boldsymbol{\Sigma}$ & $\%$ & $\boldsymbol{\Sigma}$ & $\%$ & $\boldsymbol{\Sigma}$ & $\%$ & $\boldsymbol{\Sigma}$ & $\%$ \\
\hline Sebelum & 0 & 0 & 9 & 25,7 & 26 & 74,3 & 35 & 10 \\
& & & & & & & & 0 \\
\hline Sesudah & 29 & 82,9 & 6 & 17,1 & 0 & 0 & 35 & 10 \\
& & & & & & & & 0 \\
\hline
\end{tabular}


Tabel 2 menunjukkan sebagian besar keterampilan siswa sebelum dilakukan penyuluhan dalam kategori kurang yaitu sebanyak 26 siswa $(74,3 \%)$. Presentase keterampilan mencuci tangan dalam kategori baik adalah $0 \%$. Setelah dilakukan penyuluhan cuci tangan dengan menggunakan video atraktif, Sebagian besar siswa dalam kategori Baik yaitu sebanyak 29 orang (82,9\%) dan tidak ada siswa dalam kategori keterampilan kurang.

Analisis bivariat dilakukan untuk mengetahui pengaruh penyuluhan cuci tangan menggunakan media video atraktif terhadap keterampilan cuci tangan pada siswa Madrasah Diniyah Awaliyah Belawang yang digambarkan dalam tabel 3.

Tabel 3 Gambaran Skor Keterampilan Mencuci Tangan responden $(n=35)$

\begin{tabular}{cccccc}
\hline Kategori & Median & Mean & Min & Max & $\begin{array}{c}P \\
\text { value }\end{array}$ \\
\hline Sebelum & 50 & 54 & 50 & 70 & 0.000 \\
Sesudah & 95 & 91 & 65 & 100 & \\
\hline
\end{tabular}

Tabel 3 menunjukkan bahwa terdapat peningkatan rata-rata nilai keterampilan cuci tangan setelah dilakukan penyuluhan menggunakan media video atraktif. Nilai ratarata siswa sebelum dilakukan penyuluhan media video atraktif sebesar 54 dan terjadi peningkatan menjadi 91 setelah dilakukan penyuluhan. Nilai terendah sebelum dilakukan cuci tangan adalah sebesar 50 dan meningkat setelah dilakukan penyuluhan media atraktif menjadi 65.

Hasil penelitian tersebut diperkuat oleh hasil perbedaan melalui nilai uji beda Wilcoxon Signed Rank Test didapatkan nilai $p$ value $(0,000)$ dimana nilai $p$ value $<0,05$ sehingga dapat disimpulkan bahwa ada pengaruh penyuluhan cuci tangan menggunakan media video atraktif terhadap keterampilan cuci tangan pada siswa Madrasah Diniyah Awaliyah Belawang Barito Kuala Kalimantan Selatan..

\section{PEMBAHASAN}

Hasil penelitian menunjukkan responden lakilaki dan perempuan berjumlah seimbang, yaitu
18 responden perempuan dan 17 responden laki-laki. Jenis kelamin akan mempengaruhi tingkat pemahaman siswa terhadap pengaruh keterampilan cuci tangan. Dina dalam Fatmawati (2017) mengungkapkan di dalam penelitiannya bahwa perbedaan laki-laki dan perempuan bukan hanya tampak di masyarakat tapi juga di lingkungan sekolah. Siswa laki-laki dan perempuan berbeda dalam menangkap suatu pembelajaran di kelas. Hal ini dapat dilihat pada proses pembelajaran, kebanyakan siswa perempuan yang mengikuti pelajaran terlihat antusias dan menguasai materi yang disampaikan guru dalam proses pembelajaran di dalam kelas, sedangkan kebanyakan siswa laki-laki terlihat kurang berminat dan kurang mengusai materi yang disampaikan guru dalam pelajaran.

Sebelum dilakukan penyuluhan dalam kategori kurang yaitu sebanyak 26 siswa (74,3\%). Kondisi ini dapat terjadi karena belum adanya pendidikan kesehatan mengenai teknik mencuci tangan yang tepat. Minimnya informasi siswa tentang keterampilan cuci tangan bagi siswa Madrasah Diniyah Awaliyah Belawang yang beranggapan bahwa mencuci tangan hanya sekedar membasahi tangan tanpa sabun menunjukkan indikator pengetahuan siswa tentang mencuci tangan masih banyak yang kurang (74,3\%).

Siswa melakukan cuci tangan hanya ketika tangan kotor dan tidak menggunakan sabun, hal ini sejalan dengan hasil penelitian Karala (2015) yang menyebutkan bahwa sebagian besar pengunjung RS dalam penelitiannya tidak melakukan cuci tangan, mereka melakukan cuci tangan hanya pada saat tangan kotor dan keterampilan cuci tangan dengan sabun dan hand rub masih kurang.

Mencuci tangan tidak hanya sekedar membasahi tangan, sehingga sangat penting bagi siswa untuk mendapatkan edukasi mengenai keterampilan mencuci tangan yang tepat dengan metode yang tepat agar siswa dapat dengan mudah menangkap materi pembelajaran dengan tepat dan cepat. Media Video merupakan media pembelajaran yang dapat dilihat dengan menggunakan indra penglihatan dan didengar dengan menggunakan indera pendengaran. Sebagai 
sebuah media pembelajaran, video efektif digunakan untuk proses pembelajaran secara masal, individu maupun kelompok (Daryanto, 2012).

Setelah dilakukan penyuluhan cuci tangan dengan menggunakan video atraktif, Sebagian besar siswa dalam kategori Baik (82,9\%) dan tidak ada siswa dalam kategori keterampilan kurang. Hasil penelitian ini menunjukkan adanya peningkatan hasil belajar siswa setelah diberikan penyuluhan mencuci tangan dengan menggunakan video atraktif. Hasil belajar siswa yang diajar menggunakan video atraktif akan meningkat lebih tinggi dari pada hasil belajar yang diajar tanpa media ini. Pembelajaran dengan menggunakan media audio visual lebih baik dalam hal meningkatkan hasil belajar siswa daripada pembelajaran tanpa menggunakan media audio visual (Irfan et. Al., 2016)

Menurut teori Edgar Dale pada teori Kerucut Pengalaman, dijelaskan bahwa Semakin banyak panca indera yang digunakan siswa saat belajar, maka proses belajar tersebut akan lebih mudah diserap oleh siswa. Pada kerucut pengalaman dari Edgar Dale, video terletak pada bagian tengah pada kategori "Video/Film". Posisi tersebut mengartikan bahwa media video lebih baik daripada media gambar dan media audio.

Pada penelitian ini, penyuluhan mencuci tangan kepada siswa diberikan dengan media video atraktif cuci tangan 6 langkah yang dinilai baku dan sesuai dengan WHO guidesline 2009 dan Kemenkes RI, hasilnya diperoleh peningkatan keterampilan siswa dalam melakukan cuci tangan sebagian besar menjadi baik yaitu $82,9 \%$ dan tidak ada siswa dalam kategori keterampilan kurang.

Peningkatan keterampilan siswa dalam melakukan cuci tangan tersebut diperkuat oleh hasil perbedaan melalui nilai uji beda Wilcoxon Signed Rank Test didapatkan nilai $p$ value $(0,000)$ dengan nilai $p$ value $<0,05$ yang berarti ada pengaruh penyuluhan cuci tangan menggunakan media video atraktif terhadap keterampilan cuci tangan. Video memiliki suara berupa alunan musik, ilustrasi penjelas, serta suara yang diambil dari kondisi nyata
(Suryansyah \& Sujarwo, 2016). Penelitian ini menunjukkan bahwa siswa yang belajar melalui video atraktif dinilai dapat lebih mudah menangkap dan memahami materi pengajaran, karena siswa lebih tertarik pada alunan musik, ilustrasi penjelas : suara, animasi dan juga teks dalam sebuah video. Selain itu kegiatan penyuluhan melalui video mampu merangsang keterlibatan indera dari siswa, sehingga akan membuat mereka lebih cepat faham dengan materi yang diajarkan.

Dalam penelitian ini penyuluhan menggunakan video atraktif dapat meningkatkan keterampilan mencuci tangan dikarenakan siswa lebih mudah menerima penjelasan pada saat penyuluhan. Siswa juga menjadi lebih antusias menonton video/gambar bergerak yang menarik serta mendengar lagu sehingga lebih mudah diingat. Hal ini sejalan dengan pendapat Febriani (2017) yang dalam penelitiannya mengungkapkan video dapat menjelaskan sesuatu yang bersifat abstrak menjadi terkesan nyata sehingga video sangat efektif digunakan untuk siswa sekolah dasar yang masih berada pada tahap operasional konkret.

\section{KESIMPULAN DAN SARAN}

Hasil penelitian menunjukkan ada pengaruh penyuluhan cuci tangan menggunakan media video atraktif terhadap keterampilan cuci tangan pada siswa Madrasah Diniyah Awaliyah Belawang Barito Kuala Kalimantan Selatan. Penggunaan video atraktif dapat dilakukan untuk mempermudah siswa memahami dan mengingat keterampilan cuci tangan dengan benar.

\section{REFERENSI}

Daryanto.(2010). Media Pembelajaran. Yogyakarta: Gava Media

Direktorat Promosi Kesehatan dan Pemberdayaan Masyarakat. (2016). Gerakan PHBS Sebagai Langkah Awal Menuju Peningkatan Kualitas Kesehatan Masyarakat. Jakarta: Kementrian Kesehatan Republik Indonesia, https://promkes.kemkes.go.id/phbs

Fatmawati. (2017). Perbedaan Gaya Belajar Berdasarkan Jenis Kelamin Pada Siswa Mts Madani Pao-Pao. Makasar: Skripsi Uin Alauddin Makassar 
Febriani, C. (2017). Pengaruh Media Video terhadap Motivasi Belajar dan Hasil Belajar Kognitif Pembelajaran IPA Kelas V Sekolah Dasar. Jurnal Prima Edukasia, (Online), 5 (1): 11-21, http://journal.uny.ac.id/index.php/jpe/

Irfan., Mashudi, Murtiningsih.(2016). Perbedaan Media Audio Visual dan bukan Audio Visual terhadap Motivasi dan Hasil Belajar IPS Siswa Kelas IV. Wahana Sekolah Dasar .

Karala, A. (2015). Gambaran Pelaksanaan Cuci tangan Pengunjung Bangsal Ar-Royan PKU Muhammadiyah Yogyakarta. UMY: Skripsi

Kemenkes RI. (2010). Pedoman Perilaku Hidup Bersih dan Sehat. Jakarta: Kementrian Kesehatan Republik Indonesia
Pratiwi, I. (2015). Penggunaan media Video Pembelajaran Untuk Meningkatkan Aktifitas Siswa di Sekolah Dasar. (PGSD FKIP Universitas Islam Sultan Agung)

Sugiyono. 2008. Metode Penelitian Kuantitatif Kualitatif dan R \& D.Bandung: Alfabet

Suryansyah, T. \& Suwarjo. (2016). Pengembangan Video Pembelajaran untuk Meningkatkan Motivasi dan Hasil Belajar Kognitif Siswa Kelas IV SD. Jurnal Prima Edukasia, (Online), 4 (2): 209-221,

http://journal.uny.ac.id/index.php/ipe/article/view/ $\underline{8393}$ 